\title{
COMPORTAMENTO TÉRMICO E CARACTERIZAÇÃO MORFOLÓGICA DAS FIBRAS DE MESOCARPO E CAROÇO DO AÇAÍ (Euterpe oleracea Mart.) ${ }^{1}$
}

\author{
MARIA ALICE MARTINS², LUIZ HENRIQUE CAPPARELLI MATTOSO³, \\ JOSÉ DALTON CRUZ PESSOA ${ }^{4}$
}

RESUMO-A agroindústria do açaí gera uma grande quantidade de resíduos, constituída de caroços e fibras, o que é um grave problema ambiental e de saúde pública. O objetivo deste estudo foi estudar as fibras do mesocarpo e o caroço do fruto do açaí para sua utilização em materiais compósitos. As amostras foram caracterizadas usando análise por termogravimetria (TG/DTG) em atmosferas inerte e oxidativa, microscopia eletrônica de varredura e microscopia óptica. As fibras apresentaram boa estabilidade térmica até $230{ }^{\circ} \mathrm{C}$ e um processo de degradação em atmosfera inerte em três etapas. Em atmosfera oxidativa, as fibras apresentaram menor estabilidade térmica e uma mudança no processo de degradação de três para quatro etapas. Os resultados da análise térmica do caroço mostraram um comportamento térmico similar ao da fibra. A microscopia mostrou que as fibras presentes no fruto do açaí recobrem o caroço e possuem morfologia irregular com a presença de células do parênquima na sua superfície. O comportamento térmico das fibras do açaí é semelhante ao de outras fibras vegetais já utilizadas industrialmente na área de compósitos poliméricos, o que abre novas e promissoras áreas para sua utilização.

Termos para indexação: fibra natural, análise térmica, morfologia.

\section{THERMOGRAVIMETRIC EVALUATION OF AÇAÍ FRUIT (Euterpe oleracea Mart.) AGRO INDUSTRY WASTE}

\begin{abstract}
The açaí fruit agro industry produces a large amount of waste, mainly seeds and fibers, which is a serious environmental and public health problem. The aim of this work is to study the mesocarp fibers and the açaí fruit seed to use in composite materials. The samples have been characterized by using thermogravimetric analysis (TGA/DTG) in inert and thermo-oxidative atmospheres, scanning electron and optical microscopy. The fibers have shown good stability until $230^{\circ} \mathrm{C}$ and a three-degradation step process in inert atmosphere. In oxidative atmosphere, the fibers presented a decrease in thermal stability and a change in the decomposition process from three to four steps. For the seeds, a similar behavior was observed, although a lower thermal stability was observed when compared to the fiber. Longitudinal morphology of the fibers that cover the açaí seed is rough, and parenchyma cells can be seen on the surface. The açaí fibers exhibited a thermal behavior comparable to other natural fibers used in composites, which is promising for new applications.
\end{abstract}

Index terms: natural fibers, thermal analysis, morphology.

\section{INTRODUÇÃO}

Nas últimas décadas, a importância das fibras naturais como aditivos ou reforços para produtos poliméricos vem aumentado significativamente, devido a fatores como o alto preço das fibras sintéticas e à busca crescente por materiais de baixo custo e que sejam provenientes de fontes renováveis, possuam boas propriedades mecânicas e térmicas, e não causem danos ambientais. Devido a esta nova tendência mundial, muitos estudos têm sido realizados para a utilização destas fibras em indústrias como a de materiais, construção civil, automobilística e aeronáutica. O uso de fibras naturais tem como principais vantagens: o baixo custo; baixa abrasividade; atoxicidade, baixa densidade; baixo consumo de energia; propriedades mecânicas e termoacústicas adequadas. As vantagens destas fibras sobre as sintéticas incluem também aspectos ecológicos e sociais, em razão da melhor reciclabilidade e biodegrabilidade e do aumento da qualidade de vida dos habitantes de regiões onde é realizado o cultivo (Martins \& Joekes, 2003;

\footnotetext{
1(Trabalho 194-08). Recebido em:25-07-2008. Aceito para publicação em: 21-08-2009.

${ }^{2}$ Bolsista de pós-doutorado - Universidade Federal do ABC, Rua Santa Adélia, 166, Santo André-SP, 09210-170, a_martins1000@yahoo.com.br.

${ }_{3}^{3}$ Pesquisador - Embrapa Instrumentação Agropecuária, CP 741, São Carlos-SP, 13560-970; mattoso@cnpdia.embrapa.br.

${ }^{4}$ Pesquisador - Embrapa Instrumentação Agropecuária, CP 741, São Carlos-SP, 13560-970; dalton@cnpdia.embrapa.br (Autor para correspondência).
} 
Bledzki \& Gassan, 1999).

A palmeira Euterpe oleracea Mart., conhecida como açaizeiro, pode ser considerada como a palmeira de maior importância econômica, social e cultural da região Norte do Brasil (Queiroz \& Melém Júnior, 2001; Nascimento et al., 2008), onde o Estado do Pará se destaca como o maior produtor e consumidor (Costa et al., 2001). Segundo o IBGE (IBGE, 2007), o Brasil produziu em 2005, aproximadamente, 105.000 toneladas de frutos de açaí, sendo que cerca de $90 \%$ deste volume corresponde aos resíduos gerados após o processamento agroindustrial do fruto. Estes resíduos são constituídos basicamente do caroço e de fibras. Apesar de ser uma fonte de material lignocelulósico renovável, este resíduo representa, atualmente, um grave problema ambiental (Rogez, 2000; Rodrigues et al., 2006). Somente na cidade de Belém, são comercializados de 100.000 a 120.000 toneladas de frutos de açaí por ano, o que gera cerca de 300 toneladas por dia de lixo orgânico constituído de caroço (Rogez, 2000). Diferentes métodos têm sido investigados para a utilização do resíduo da agroindústria do açaí, como a sua utilização para geração de energia (Reis et al., 2002; Rodrigues et al., 2002), para produção de adubo (Teixeira et al., 2004) e para extração de antioxidante. Entretanto, sua caracterização física e química, e a forma para sua reutilização ainda não foram definidas.

Para ampliar e otimizar a utilização industrial do fruto do açaí e do resíduo gerado no seu processamento, realizou-se uma avaliação termogravimétrica das fibras que recobrem o caroço, pois parte destas fibras está presente no processamento do suco e também no resíduo gerado pela agroindústria do açaí. Para a utilização destes materiais em produtos poliméricos que envolvem, em geral, processos de moldagem a temperaturas acima de $150{ }^{\circ} \mathrm{C}$, é necessária uma avaliação térmica dos mesmos. Devido aos desempenhos mecânico e térmico das fibras naturais, diversos estudos estão sendo realizados para otimizar sua utilização em indústrias como a de materiais compósitos (Mishra et al., 2004) e nanocompósitos (Bhatnagar \& Sain, 2005), automobilística (Salazar, 2005) e civil (Ramakrishna \& Sundararajan, 2005). Ma et al. (2005) estudaram a influência da adição de fibras naturais em materiais biodegradáveis à base de amido para aplicação na área de embalagens e observaram que a adição das fibras aumentou a estabilidade térmica, a resistência mecânica e reduziu a absorção de umidade dos materiais obtidos.

A termogravimetria (TG) é uma técnica da análise térmica na qual a variação de massa da amostra (perda ou ganho) é determinada em função da temperatura e/ou tempo, enquanto a amostra é submetida a uma taxa controlada de aumento de temperatura. Esta técnica possibilita conhecer as alterações que o aquecimento pode provocar na massa das substâncias, permitindo estabelecer a faixa de temperatura em que elas começam a se decompor, adquirem composição química fixa, definida e constante, podendo-se também acompanhar reações como desidratação, oxidação, combustão, etc. (Canevarolo, 2004). O presente trabalho teve como objetivo avaliar o comportamento térmico e a caracterização morfológica das fibras do mesocarpo e do caroço do açaí.

\section{MATERIAL E MÉTODOS}

A caracterização térmica foi realizada por termogravimetria (TG) e por termogravimetria derivada (DTG), e a caracterização morfológica foi feita através de microscopia eletrônica de varredura (MEV) e microscopia óptica (MO).

Os frutos de açaí foram fornecidos pela Amazonfrut - Frutas da Amazônia Ltda., sendo coletados na Ilha de Murutucu, Rio Guamá, Belém-Pará. Para a realização dos ensaios, cerca de $2 \mathrm{~kg}$ de frutos foram lavados, e o pericarpo, a polpa e as fibras foram removidos manualmente para se obter o resíduo agroindustrial constituído das fibras e do caroço.

A análise térmica das fibras e do caroço do açaí foi realizada em equipamento TA Instruments Q500, a partir da temperatura de $25^{\circ} \mathrm{C}$ até $800{ }^{\circ} \mathrm{C}$, em atmosfera inerte com nitrogênio e em atmosfera termoxidativa com ar sintético (99,99\% de $\mathrm{O}_{2}$ e $\mathrm{N}_{2}$ ). Nos ensaios, foram usados fluxo de $30 \mathrm{~mL} /$ min e taxa de aquecimento de $10{ }^{\circ} \mathrm{C} / \mathrm{min}$. Para a realização dos ensaios, os frutos foram lavados, e o pericarpo, a polpa e as fibras que recobrem o caroço foram removidos manualmente. As fibras e o caroço foram separados e secos até massa constante, sendo em seguida cortados para serem colocados no portaamostra do equipamento de análise térmica. Foram utilizadas cerca de $10 \mathrm{mg}$ de amostra em cada ensaio, ensaios em duplicata.

Para a caracterização morfológica por microscopia eletrônica de varredura, amostras das fibras, cerca de $50 \mathrm{~g}$, foram imersas em uma solução de $\mathrm{NaOH}$ a $1 \mathrm{M}$, à temperatura ambiente $\left(25^{\circ} \mathrm{C}\right)$, por 12 horas, para a limpeza da superfície. Em seguida, as fibras foram filtradas e lavadas com água destilada, usando-se papel de filtro qualitativo e secas em estufa a $80{ }^{\circ} \mathrm{C}$, até massa constante. Amostras das fibras e dos frutos foram colocadas em porta-amostra, usando-se fita adesiva dupla face e circundadas com cola de prata. Após a preparação das amostras, foi feita a deposição de ouro pelo método de "Sput- 
tering”, utilizando-se de um equipamento Balzers SCD 050 Sputter Coater. A análise por microscopia foi realizada utilizando-se um microscópio de varredura, Zeiss modelo DSM 960, operando a 20 kV na modalidade de SEI (elétrons secundários). A análise por microscopia óptica foi realizada usando-se um estéreo-microscópio marca Lambda, modelo LET 3. Foram analisadas pelo menos 20 amostras por MEV e 25 por microscopia óptica.

\section{RESULTADOS E DISCUSSÃO}

A Figura 1 e a Tabela 1 indicam os resultados de termogravimetria das fibras do açaí. Em atmosfera de nitrogênio, as fibras apresentaram três processos de perda de massa; inicialmente, até $100{ }^{\circ} \mathrm{C}$, ocorreu uma pequena variação com redução de cerca de $5 \%$ em massa, devido à perda de umidade. Em seguida, houve uma variação acentuada a partir de $230^{\circ} \mathrm{C}$, com perda de $65 \%$ da massa, atribuída à decomposição da hemicelulose e à quebra de ligações da celulose. A terceira etapa na variação de massa ocorreu, a partir de $370{ }^{\circ} \mathrm{C}$, devido à decomposição final da celulose e da lignina, com teor final de resíduos de 18\%. A temperatura na qual 50\% de decomposição da massa ocorre, é considerada como um índice da estabilidade térmica do material (Canevarolo, 2004). Para as amostras estudadas, observou-se que esta redução da massa inicial ocorreu em $350{ }^{\circ} \mathrm{C}$.

$\mathrm{Na}$ termogravimetria derivada (DTG), as curvas são registradas a partir das curvas de TG e correspondem à derivada primeira da variação de massa em relação ao tempo ( $\mathrm{dm} / \mathrm{dt})$, a qual é registrada em função da temperatura ou do tempo. Transforma uma inflexão num pico, cuja área é proporcional à variação de massa ocorrida, além de mostrar os limites de temperatura onde cada evento ocorre (inicial: Ti) e (final: Tf), respectivamente, assim como a temperatura de pico que indica a inflexão máxima da curva, (Tabela 1) e permite a determinação do número de etapas de reação em caso de processos consecutivos (Canevarolo, 2004). A curva de DTG, para o ensaio em atmosfera de $\mathrm{N}_{2}$ ou inerte, mostrou um pico inicial em $50{ }^{\circ} \mathrm{C}$, correspondente à eliminação de água. Depois deste pico, observa-se que as fibras apresentaram uma degradação em três etapas: um primeiro pico a 280 ${ }^{\circ} \mathrm{C}$, relacionado à despolimerização da hemicelulose, e um segundo pico a $345^{\circ} \mathrm{C}$, atribuído à decomposição da celulose e da lignina; e um pequeno pico, em $610^{\circ} \mathrm{C}$, atribuído à degradação dos resíduos.

$\mathrm{Na}$ atmosfera termoxidativa ou com ar sintético, ocorreu mudança no processo de degradação das fibras em relação à de atmosfera inerte. Após a perda de massa inicial, devido à perda de umidade, ocorreram quatro etapas na degradação, dois picos a $280{ }^{\circ} \mathrm{C}$ e $320^{\circ} \mathrm{C}$, atribuídos à decomposição da hemicelulose, da celulose e da lignina; e um terceiro a $460{ }^{\circ} \mathrm{C}$, atribuído à degradação final do material; e um pequeno a $590{ }^{\circ} \mathrm{C}$, devido à degradação dos resíduos finais. Observa-se também que, em atmosfera de ar, a estabilidade térmica das fibras e o teor de resíduos, cerca de 3\%, são menores que em atmosfera inerte.

Neste trabalho, os resultados de análise térmica mostraram que as fibras do açaí apresentam boa estabilidade térmica até $230^{\circ} \mathrm{C}$, com processo de degradação em três etapas, o que é semelhante ao observado para as principais fibras naturais já utilizadas industrialmente, como o sisal (Chand et al., 1987) e o coco (Varma et al., 1986), o que abre novas e promissoras perspectivas para sua utilização.

Os resultados de TG e de DTG para o caroço do açaí, em atmosfera inerte de nitrogênio e em atmosfera termoxidativa de ar sintético, são apresentados na Figura 2 e detalhadamente na Tabela 2. Observa-se que diferentemente do observado para a fibra, a atmosfera na qual foi realizado o ensaio, não influenciou na estabilidade térmica do caroço até $400^{\circ} \mathrm{C}$. Em atmosfera oxidativa, após a redução de massa inicial, atribuída à perda de umidade, o processo de degradação mudou de três para quatro etapas, e ocorreu uma redução acentuada no teor de resíduos similar ao que aconteceu para as fibras. O caroço apresentou boa estabilidade térmica até $200{ }^{\circ} \mathrm{C}$, apresentando uma perda de massa de $10 \%$. A partir desta temperatura, inicia-se o processo de degradação da hemicelulose, da celulose e da lignina. A estabilidade térmica do caroço é menor que a das fibras, sendo que, a $300{ }^{\circ} \mathrm{C}$, sua massa foi reduzida em $50 \%$, enquanto para as fibras, esta porcentagem de redução da massa inicial ocorreu a $350{ }^{\circ} \mathrm{C}$.

Os resultados do comportamento térmico da fibra e do caroço sugerem que as fibras de açaí podem ser utilizadas industrialmente, em áreas como a indústria automobilística e de materiais, como estão sendo usadas as fibras de sisal e coco para reforço em materiais compósitos. O resíduo gerado pela agroindústria do açaí, a fibra e o caroço, também poderão ser usados para a produção de energia. Outra alternativa para a utilização do caroço é seu uso como biocombustível na forma de briquetes (Reis et al., 2002; Rodrigues et al., 2002).

Nas fotomicrografias do fruto obtidas por microscopia óptica, mostradas na Figura 3, observa-se a forma compacta e coesa com que as fibras recobrem o caroço. Observa-se também que, em algumas regiões, elas estão alinhadas de forma regular e, em outras, este alinhamento não é homogêneo. Os 
frutos têm forma arredondada, com um diâmetro de 1 a $2 \mathrm{~cm}$ e massa de 0,8 a 2,3g; o epicarpo ou casca é fino, e o mesocarpo tem uma espessura de 1 a $2 \mathrm{~mm}$; a polpa representa de 5 a $15 \%$ do volume do fruto, dependendo da variedade e da maturidade do fruto, e o caroço é envolto por um feixe de fibra, concordando com o descrito por Rogez (Rogez, 2000). Micrografias representativas do fruto do açaí obtidas por MEV são apresentadas na Figura 4, onde se podem ver as fibras do mesocarpo localizadas entre a polpa e o caroço. A partir das micrografias, pode-se observar que o epicarpo é delgado em relação à polpa e que as fibras recobrem o caroço de forma compacta e, em algumas regiões alinhadas, sendo que o maior volume dos frutos é constituído pelo caroço.
A Figura 5 apresenta micrografias representativas das fibras que recobrem o caroço do açaí. A Figura 5-A mostra uma parte do feixe destas fibras após o tratamento com $\mathrm{NaOH}$, podendo-se observar que elas não possuem superfície homogênea ou lisa e são recobertas com células do parênquima. Observase também que possuem forma irregular, não podendo ser classificadas como esféricas ou elípticas. Na Figura 5-B, que é uma micrografia num aumento maior, vê-se em detalhe os orifícios denominados canais de pontuação presentes em toda a extensão das fibras e células do parênquima que recobrem a superfície.

TABELA 1 - Termogravimetria das fibras do açaí em atmosfera inerte de nitrogênio e em atmosfera oxidante de ar sintético.

\begin{tabular}{ccccc}
\hline & Faixa de temperatura & $\begin{array}{c}\text { Temperatura } \\
\text { máxima }\end{array}$ & $\begin{array}{c}\text { Percentagem de } \\
\text { perda de massa }\end{array}$ & $\begin{array}{c}\text { Percentagem de } \\
\text { resíduo }\end{array}$ \\
& $25-100$ & 50 & 5 & 95 \\
Nitrogênio & $100-230$ & - & - & 95 \\
& $230-300$ & 280 & 23 & 72 \\
& $300-400$ & 345 & 35 & 37 \\
\multirow{4}{*}{ Ar } & $400-800$ & 610 & 19 & 18 \\
& $25-100$ & 40 & 8 & 92 \\
& $100-230$ & - & 4 & 88 \\
& $230-300$ & 280 & 23 & 30 \\
& $300-400$ & 320 & 35 & 3 \\
\hline
\end{tabular}

TABELA 2 - Termogravimetria do caroço do açaí em atmosfera inerte de nitrogênio e em atmosfera oxidante de ar sintético.

\begin{tabular}{ccccc}
\hline & Faixa de temperatura & $\begin{array}{c}\text { Temperatura } \\
\text { máxima }\end{array}$ & $\begin{array}{c}\text { Percentagem de } \\
\text { perda de massa }\end{array}$ & $\begin{array}{c}\text { Percentagem de } \\
\text { resíduo }\end{array}$ \\
\multirow{3}{*}{ Nitrogênio } & 70 & 3 & 97 \\
& $25-100$ & 225 & 20 & 77 \\
& $100-250$ & 270 & 32 & 45 \\
& $250-350$ & 375 & 15 & 30 \\
\multirow{3}{*}{$\mathrm{Ar}$} & $350-800$ & 70 & 3 & 97 \\
& $25-100$ & 215 & 20 & 77 \\
& $100-250$ & 270 & 32 & 45 \\
& $250-350$ & 445 & 27 & 18 \\
\hline
\end{tabular}



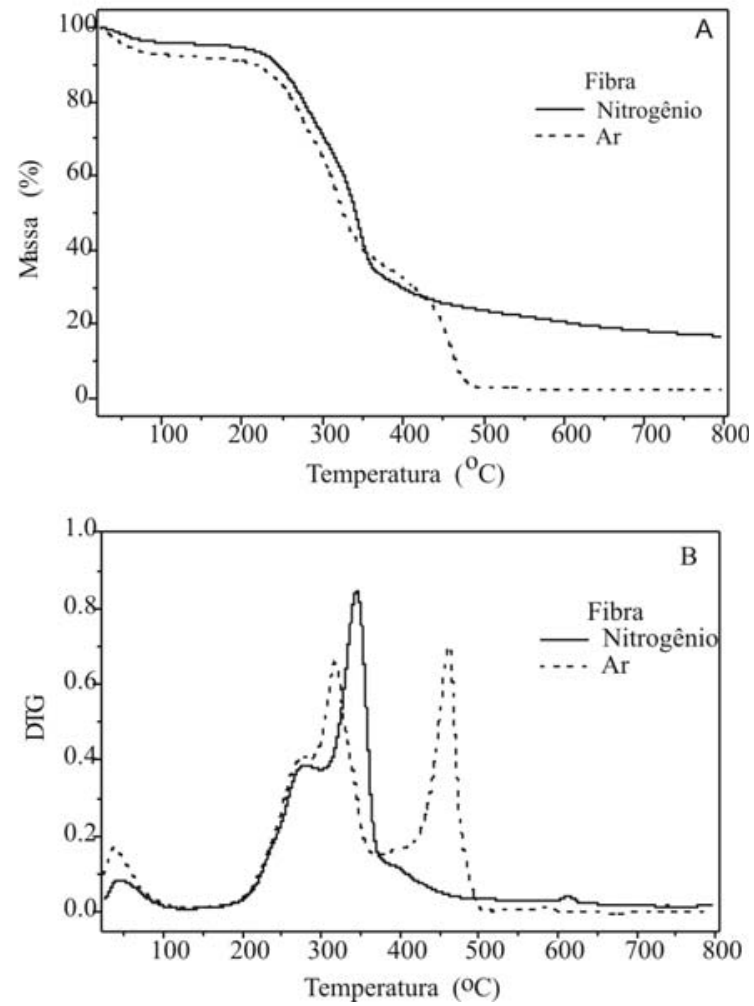

FIGURA 1 - Curvas de TG (A) e de termogravimetria derivada (DTG) (B) das fibras do mesocarpo do açaí em atmosferas de nitrogênio e ar sintético, com taxa de aquecimento de $10^{\circ} \mathrm{C} / \mathrm{min}$.
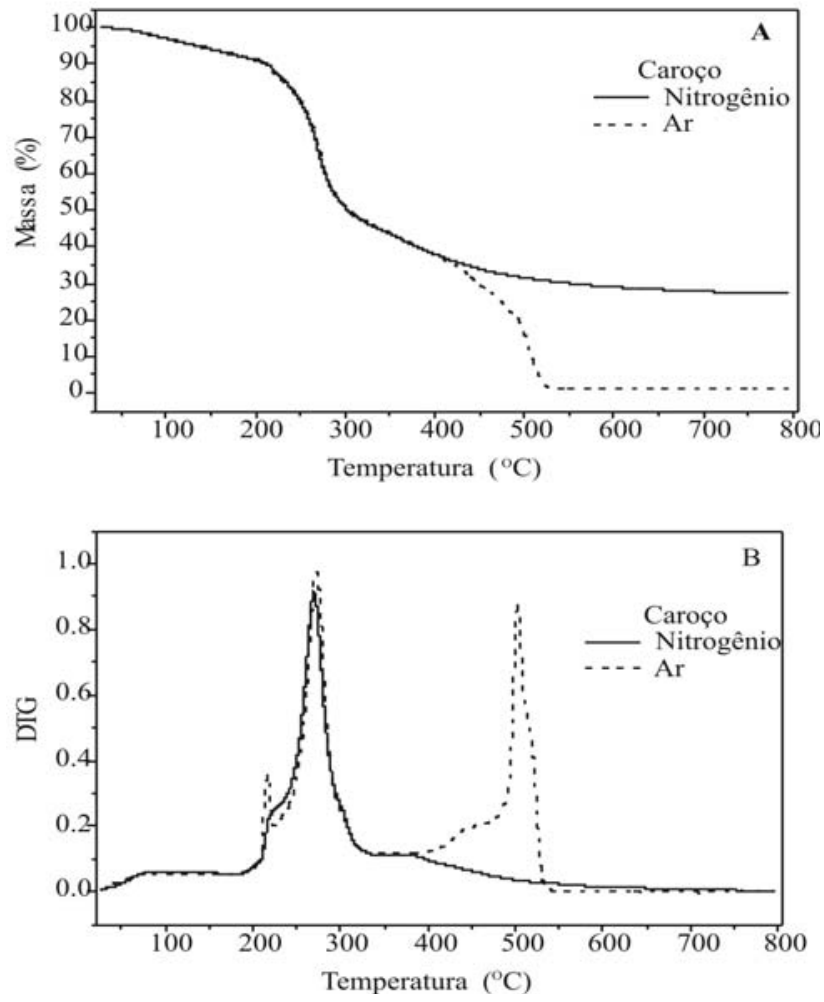

FIGURA 2 - Curvas de TG (A) e de termogravimetria derivada (DTG) (B) do caroço do açaí em atmosfera de nitrogênio e ar sintético, com taxa de aquecimento de $10^{\circ} \mathrm{C} / \mathrm{min}$. 

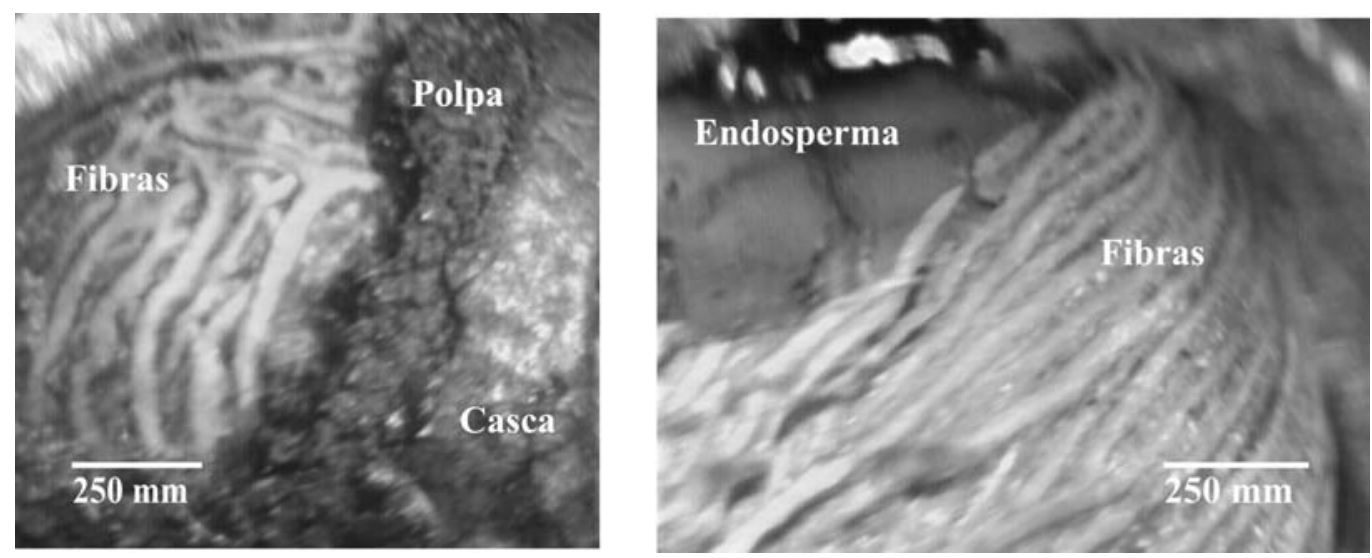

FIGURA 3 - Fotomicrografias obtidas por microscopia óptica do fruto do açaí. 4x.
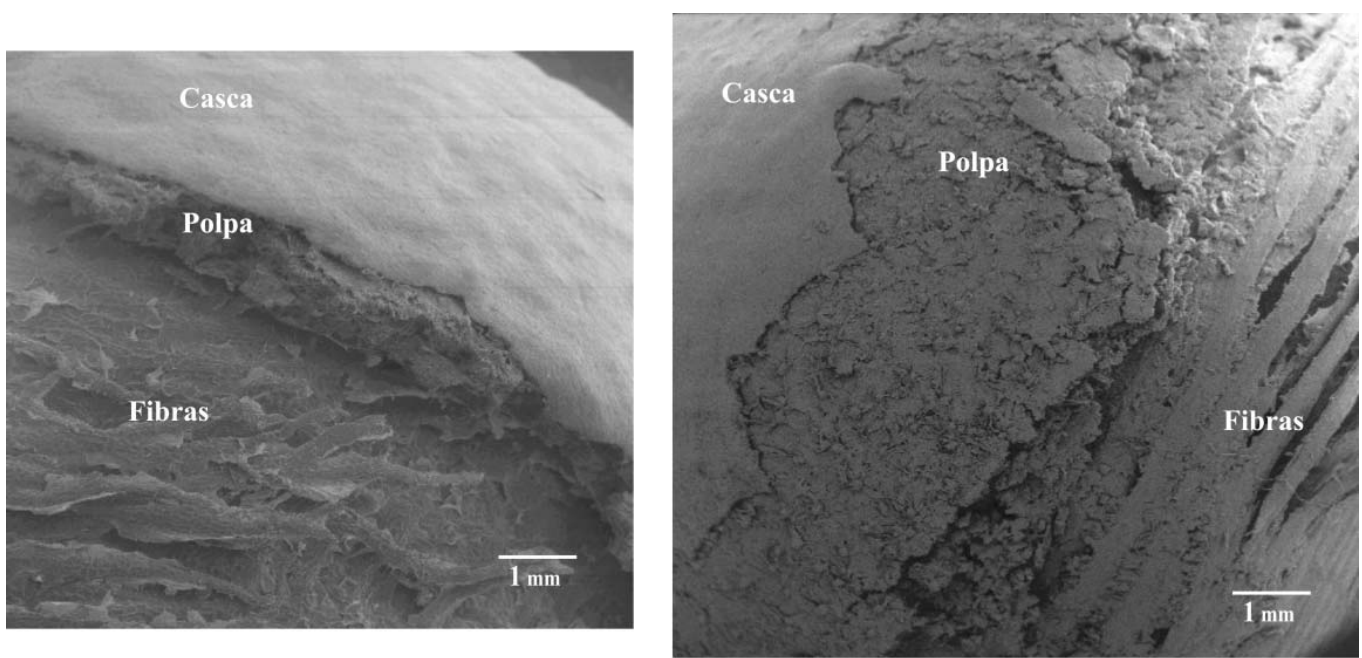

FIGURA 4 - Micrografias obtidas por microscopia eletrônica de varredura do fruto do açaí.
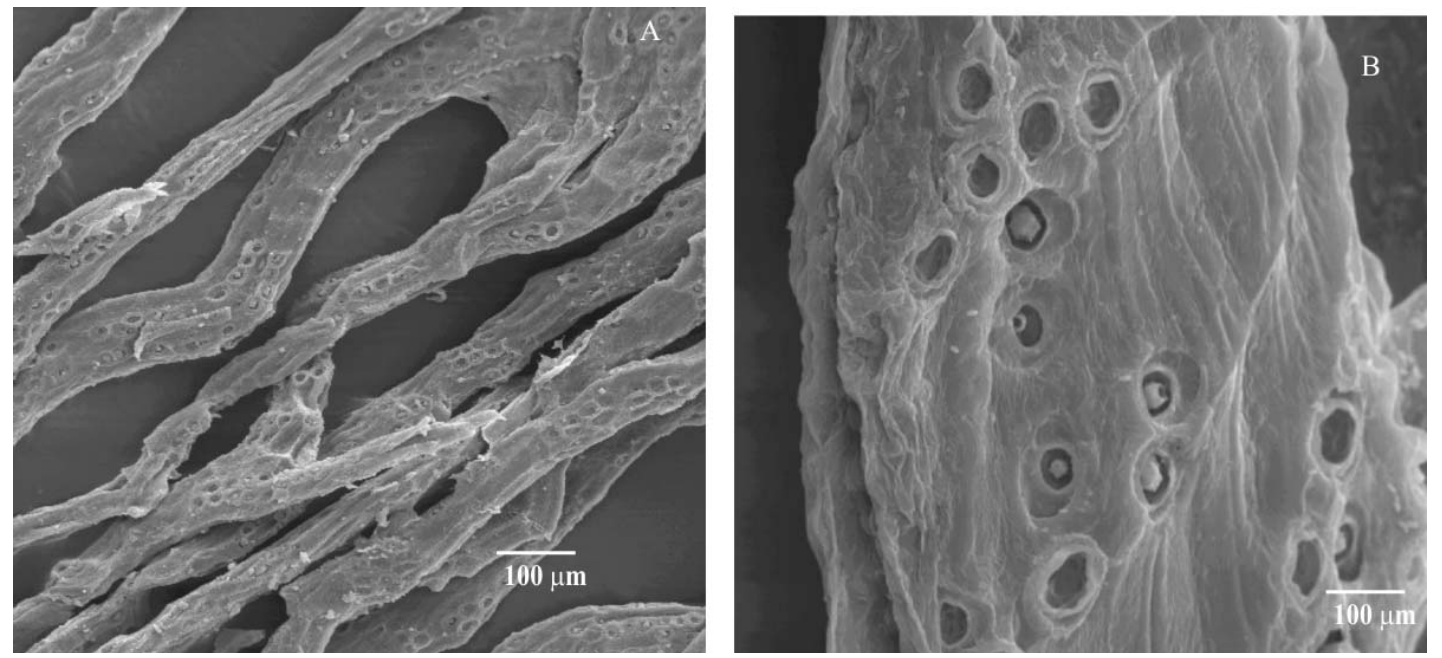

FIGURA 5 - Micrografias obtidas por microscopia eletrônica de varredura da fibra do mesocarpo do açaí. 


\section{CONCLUSÕES}

As fibras do açaí apresentam boa estabilidade térmica até $230{ }^{\circ} \mathrm{C}$, com processo de degradação em três etapas. Em atmosfera termoxidativa, o processo de degradação das fibras e do caroço mudou de três para quatro etapas, com redução acentuada no teor de resíduos. A estabilidade térmica do caroço é menor que a das fibras, sendo que a redução de $50 \%$ da massa inicial ocorreu a $300^{\circ} \mathrm{C}$ e $350^{\circ} \mathrm{C}$, respectivamente. O comportamento térmico apresentado pela fibra de açaí é semelhante ao das principais fibras naturais já usadas industrialmente, abrindo perspectivas promissoras para sua utilização. O estudo por MO e MEV mostrou que o epicarpo do fruto é delgado em relação à polpa e que as fibras recobrem o caroço de forma compacta e, em algumas regiões alinhadas, observou-se também que as fibras apresentam canais de pontuação presentes em toda sua extensão e células do parênquima recobrem a sua superfície.

\section{AGRADECIMENTOS}

Os autores agradecem à FAPESP e ao CNPq, pelo apoio financeiro, e à Amazonfrut - Frutas da Amazônia Ltda., pelo fornecimento dos frutos.

\section{REFERÊNCIAS}

BHATNAGAR, A.; SAIN, M. Processing of cellulose nanofiber-reinforced composites. Journal of Reinforced Plastics and Composites, Stanford University, v.24, n.12, p.1259-1268, 2005.

BLEDZKI, A.K.; GASSAN, J. Composites reinforced with cellulose based fibres. Progress in Polymer Science, Elmsford, v.24, n.2, p.221-274, 1999.

CANEVAROLO Jr., S.V. Técnicas de caracterização de polímeros. São Paulo: Artliber Editora, 2004. 445p.

CHAND, N.; SOOD, S.; SINGH, D.K.; ROHATGI, P.K. Structural and thermal studies on sisal fiber. Journal of Thermal Analysis, Dordrecht, v.32, n.2, p.595-599, 1987.

COSTA, M.R.; OLIVEIRA, M.S.P.; MOURA, E.F. Variabilidade genética em açaizeiro (Euterpe oleraceae Mart.). Biotecnologia Ciência e Desenvolvimento, Brasília, v. 4, n.21, p.46-50, 2001.
IBGE - Instituto Brasileiro de Geografia e Estatística. Produção da extração vegetal da Silvicultura 2005. Disponível em: <www.ibge.gov.br>. Acesso em: 15 ago. 2007.

MA, X.F.; YU, J.G.; KENNEDY, J.F. Studies on the properties of natural fibers-reinforced thermoplastic starch composites. Carbohydrate Polymers, Kidlington, v.62, n.1, p.19-24, 2005.

MARTINS, M.A.; JOEKES, I. Tire rubber-sisal composites: effect of mercerization and acetylation on reinforcement. Journal of Applied Polymer Science, Cleveland, v.89, n.9, p.2507-2515, 2003.

MISHRA, S.; MOHANTY, A.K.; DRZAL, L.T.; MISRA, M.; GEORG HINRICHSEN, G. A review on pineapple leaf fibers, sisal fibers and their biocomposites. Macromolecular Materials and Engineering, Weinheim, v.289, n.11, p.955-974, 2004.

NASCIMENTO, R.J.S.; COURI, S.; ANTONIASSI, R.; FREITAS, S.P. Composição em ácidos graxos do óleo da polpa de açaí extraído com enzimas e com hexano. Revista Brasileira de Fruticultura, Jaboticabal, v.30, n.2, p.498-502, 2008.

QUEIROZ, J.A.L.; MELÉM Jr., N.J. Efeito do tamanho do recipiente sobre o desenvolvimento de mudas de açaí (Euterpe oleracea Mart.). Revista Brasileira de Fruticultura, Jaboticabal, v.23, n.2, p.460-462, 2001.

RAMAKRISHNA, G.; SUNDARARAJAN, T. Studies on the durability of natural fibres and the effect of corroded fibres on the strength of mortar. Cement and Concrete Composites, Davis, v.27, n.5, p.575-582, 2005.

REIS, B.O.; SILVA, I.T.; SILVA, I.M.O.; ROCHA, B.R.P. Produção de briquetes energéticos a partir de caroços de açaí. In: ENCONTRO DE ENERGIA NO MEIO RURAL, 4., 2002, Campinas. Anais...

RODRIGUES, L.D.; SILVA, I.T.; ROCHA, B.R.P.; SILVA, I.M.O. Uso de briquetes compostos para produção de energia no Estado do Pará. In: ENCONTRO DE ENERGIA NO MEIO RURAL, 2002, 4., Campinas. Anais...

RODRIGUES, R.B.; LICHTENTHÄLER, R.; ZIMMERMANN, B.F.; PAPAGIANNOPOULOS, M.; FABRICIUS, H.; MARX, F. Total oxidant 
scavenging capacity of Euterpe oleracea Mart. (açaí) seeds and identification of their polyphenolic compounds. Journal of Agricultural and Food Chemistry, Washington, v.54, n.12, p.4162-4167, 2006.

ROGEZ, H. Açaí: preparo, composição e melhoramento da conservação. Belém: EDFPA, 2000. 313p.

SALAZAR, V.L.P.; CARASCHI, J.C.; LEÃO, A.L. Avaliação dos produtos de emissão a partir da pirólise de assentos automotivos feitos de fibra de coco e de espuma de poliuretano. Engenharia Sanitária e Ambiental, Rio de Janeiro, v.10, n.2, p.162-166, 2005.
TEIXEIRA, L.B. de OLIVEIRA, R.F.; FURLAN Jr.; J.; GERMANO, V.L.C. Processo de compostagem a partir de lixo orgânico urbano e caroço de açaí. Belém: Embrapa Amazônia Oriental, 2004. 4p. (Circular Técnica, 105)

VARMA, D.S.; VARMA, M.; VARMA, I.K. Thermal-behavior of coir fibers. Thermochimica Acta, Amsterdan, v.108, p.199-210, 1986. 